\title{
Interactive Effects of Morphine on HIV Infection: Role in HIV-Associated Neurocognitive Disorder
}

\author{
Pichili Vijaya Bhaskar Reddy, ${ }^{1}$ Sudheesh Pilakka-Kanthikeel, ${ }^{1}$ Shailendra K. Saxena, ${ }^{2}$ \\ Zainulabedin Saiyed, ${ }^{1}$ and Madhavan P. N. Nair ${ }^{1}$ \\ ${ }^{1}$ Department of Immunology, Institute of NeuroImmune Pharmacology, Herbert Wertheim College of Medicine, \\ Florida International University, Miami, FL 33199, USA \\ ${ }^{2}$ Centre for Cellular \& Molecular Biology, Uppal Road, Hyderabad 500007, India
}

Correspondence should be addressed to Madhavan P. N. Nair, nairm@fiu.edu

Received 16 September 2011; Revised 13 February 2012; Accepted 2 March 2012

Academic Editor: Marjorie Robert-Guroff

Copyright (C) 2012 Pichili Vijaya Bhaskar Reddy et al. This is an open access article distributed under the Creative Commons Attribution License, which permits unrestricted use, distribution, and reproduction in any medium, provided the original work is properly cited.

\begin{abstract}
HIV epidemic continues to be a severe public health problem and concern within USA and across the globe with about 33 million people infected with HIV. The frequency of drug abuse among HIV infected patients is rapidly increasing and is another major issue since injection drug users are at a greater risk of developing HIV associated neurocognitive dysfunctions compared to nondrug users infected with HIV. Brain is a major target for many of the recreational drugs and HIV. Evidences suggest that opiate drug abuse is a risk factor in HIV infection, neural dysfunction and progression to AIDS. The information available on the role of morphine as a cofactor in the neuropathogenesis of HIV is scanty. This review summarizes the results that help in understanding the role of morphine use in HIV infection and neural dysfunction. Studies show that morphine enhances HIV-1 infection by suppressing IL-8, downregulating chemokines with reciprocal upregulation of HIV coreceptors. Morphine also activates MAPK signaling and downregulates cAMP response element-binding protein (CREB). Better understanding on the role of morphine in HIV infection and mechanisms through which morphine mediates its effects may help in devising novel therapeutic strategies against HIV-1 infection in opiate using HIV-infected population.
\end{abstract}

\section{Introduction}

The HIV epidemic continues to be the most severe public health problem and concern within USA and across the globe with about 33 million people infected with HIV. During the later stages of the disease, HIV-1-infected patients suffer from a wide range of neurological and neurocognitive disorders collectively known as HIV-associated neurocognitive disorder (HAND) [1-6]). Severe neuropathological changes resulting in significantly higher neurocognitive dysfunctions have been linked with other infections or illicit drug abuse. According to recent studies, it is believed that illicit drug abuse is one of the leading causes for transmission of HIV within USA [7-13]. Injection drug users are at a higher risk of getting infected with HIV and have greater chances of developing neurological abnormalities and other opportunistic infections as a result of sharing contaminated needles and increased risky sexual behavior [14-16]. Combined HIV infection along with opiate drug addiction has gained attention in the recent years and is an emerging problem in the post-HAART era since these individuals live longer; however, the associated neurological abnormalities remain among most of the clinical disorders observed in HIVinfected patients $[8-10,12,17,18]$.

Opioids represent a major class of addictive drugs of abuse among which heroin is the most abused substance. Since heroin is converted to morphine in the brain, morphine has been the preferred choice of study [19]. Morphine has been demonstrated to severely affect the immune system by modulating the functions of variety of cells like phagocytes, T cells, and dendritic cells [20-24].

Opioid drugs and HIV viral proteins act in synergy and thus lead to greater immunosuppression and hence these drugs are called cofactors for HIV infection. Selective regions 
of the brain such as striatum and hippocampus highly express opioid receptors and have been associated with increased viral titers in HIV-infected patients [19, 25, 26]. Apart from modifying the neural response to HIV directly, opiate drugs also affect the endogenous opioid peptide levels which in turn modulate the functions of the central nervous system $[19,25]$. Though different kinds of opioid receptors exist, the commonly used opioids such as morphine and opioid agonists like naloxone bind to the $\mu$ opioid receptor with greatest affinity. This paper summarizes the results from our and other laboratories supporting the hypothesis that morphine enhances HIV-1 infectivity and that it aids in the neuropathogenesis of HAND.

\section{Morphine Induces Apoptosis}

Chronic abuse of opiate drugs significantly increases the viral titers and affects the CD4 T cells in HIV-infected subjects $[27,28]$. Apoptosis has been postulated to be a cause for the significant loss of $\mathrm{T}$ cells, thereby worsening the clinical condition of HIV-infected patients. HIV virus and many of the proteins that are encoded by HIV genome including gp120, Tat, Nef, Vpr, Vpu, and HIV protease have been found to have pro- and/or antiapoptotic qualities [29-32]. Peterson and colleagues have shown that morphine increases HIV-1 replication in human peripheral blood mononuclear cells (PBMCs) that are chronically infected with HIV [33, 34]. Our studies for the first time have indicated that PBMCs treated with morphine induce significant apoptosis (Figure 1). Cells treated with morphine showed evident DNA fragmentation as compared to their respective controls. Our studies in total suggested that morphine can cause immunosuppression during HIV infection possibly by inducing apoptosis either independently or by acting as a cofactor in the pathogenesis of HIV infection [35]. In another study, Moorman et al. [36] reported that freshly isolated human PBMCs when infected with either HIV-1 gp120/anti-gp120 or morphine $(3 \mu \mathrm{M})$ alone did not cause a significant apoptosis. However, a combined infection with HIV-1 gp120/antigp120 in the presence of morphine significantly enhanced the percentage of apoptotic cells. Opiate drugs bind to $\mu$ opioid receptors present on different kinds of immune cells and thus affect the inflammatory responses including macrophage modulation and production of different kinds of cytokines $[33,37,38]$. Upregulation of $\mu$ opioid receptor has been suggested to play an important role in HIV infection [39]. In correlation with these results, studies of Moorman et al. have demonstrated that mice lacking $\mu$ opioid receptors showed significantly lowered apoptosis as compared to wild types when treated with HIV-1 gp120 and morphine [36].

Although morphine primarily exerts its effect by binding to the $\mu$ opioid receptors, it also can bind to other receptors such as kappa and delta. Studies have shown that treatment of $\mathrm{CD}^{+}{ }^{+} \mathrm{T}$ lymphocytes with synthetic kappa opioid receptor (KOR) ligands significantly suppressed HIV p24 and CXCR4 expression and such inhibitory action of the KOR ligand was further shown to be operative in the initial phase of the virus entry into the cell [40]. In addition, pretreatment of $\mathrm{CD}^{+}$lymphocytes with U50,488 inhibited HIV-1

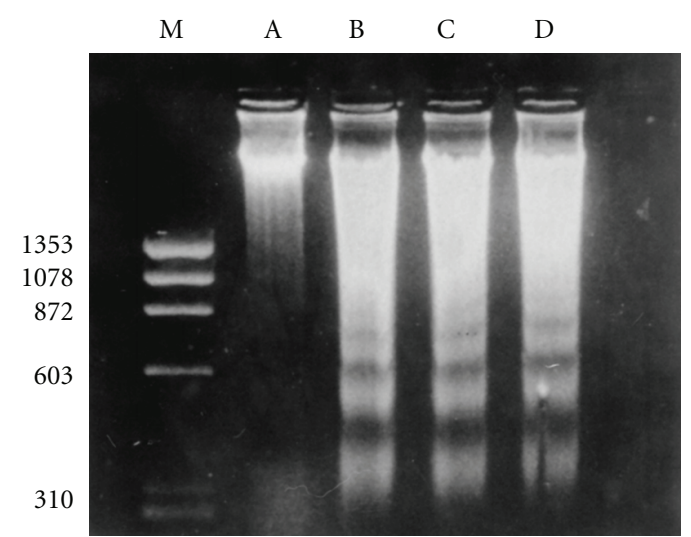

Figure 1: Morphine induces apoptosis of human PBMCs. PBMCs were cultured alone or with different concentrations of morphine for $60 \mathrm{~h}$. Total DNA was extracted and electrophoresed on a $1.8 \%$ agarose gel in the presence of ethidium bromide. Arrows indicate fragmented DNA. Lane A, control culture; lanes B and C, cells treated with morphine at concentrations of $10^{-7}$ and $10^{-9} \mathrm{M}$ respectively; lane $\mathrm{D}$, cells treated with cortisol at $0.2 \mathrm{mg} / \mathrm{mL}$ (positive control); lane M, molecular weight marker. Copyright (c) 1997, American Society for Microbiology. This figure is reproduced from the original article published in Clinical and diagnostic laboratory immunology, Nair et al. [35].

envelope glycoprotein-mediated membrane fusion in a dosedependent manner and such inhibitory activity was blocked by the KOR antagonist nor-binaltorphimine [41].

Morphine can cross the blood brain barrier (BBB) causing cerebral dysfunction. Recent studies have demonstrated that morphine induces apoptosis in human neurons and such effect was further enhanced in combination with HIV [42-44]. Further, studies have shown that morphine enhances HIV-Tat-induced toxicity in human neurons through the opioid receptors by increasing caspase- 3 activity and decreasing $\mathrm{BCl} 2 / \mathrm{BAX}$ ratio indicating that the cells progressed towards apoptosis $[42,44]$. Further, addressing the combined effects of morphine and HIV, Hauser et al. [42] have demonstrated that Tat alone or morphine alone resulted in an enhanced immunochemical expression of the active caspase-3 in young oligodendrocytes in vitro. However, the expression of caspase- 3 was much higher and additive when exposed to Tat and morphine together and such upregulation was specifically blocked by the opioid antagonist naloxone. Further investigations employing the transgenic mice conditionally expressing HIV-Tat in the astroglia revealed that Tat and morphine showed additive effects in oligodendrocytes [42].

P38 MAPK has been shown to be involved in HIVinduced neuronal apoptosis [45]. The mechanisms involved in mediating the synergistic effect of HIV and morphine have also been shown to involve p38 MAPK $[43,45,46]$. In support of this hypothesis, pretreatment with SB203580, an inhibitor of MAPK, significantly attenuated the synergistic effect of HIV viral proteins and morphine. Further, phosphorylation of p38 MAPK by either morphine or HIV gp120 
alone was short lived as compared to a combined treatment with morphine and HIV-lgp120 [43].

\section{Morphine Alters the Cytokine Expression in Human Glial Cells}

HIV is known to infect various CNS cells like microglia, astrocytes and cause neuronal dysfunction leading to dementia. Astrocytes represent a major population of nonneuronal cells in the brain that comprise about $25-50 \%$ of the total volume of the brain. Several studies have shown the important role played by astrocytes in supporting the neurons and their function. Although astrocytes have been shown to play a vital role in the neuropathogenesis of HIV, astrocytes are not productively infected with HIV unlike other cells such as macrophages, microglia, and monocytes.

Morphine is a potential immunosuppressant that crosses the $\mathrm{BBB}$ and regulates immune responses by different mechanisms in the central nervous system. Neuroinflammation is a hallmark of HAND associated with changes in chemokine expression. As said earlier, CNS may be specifically susceptible to synergistic effects of opiate abuse and HIV infection [47-49]. $\mu$ opioid receptor has been shown to be expressed in astrocytes which may be responsible for the increased effects of opiate drugs on HIV infection mediated by mechanisms such as increased calcium and altered cytokine productions [50]. Astrocytes get activated as a result of the alteration in the cellular homeostasis thereby leading to the production of cytokines [51, 52]. IL-8 is one of the first proinflammatory chemokines that was identified and responds in combination with other inflammatory factors [53-56]. IL-8 is known to inhibit the HIV infection by blocking its specific receptor CXCR2 [57, 58]. Our studies have shown that morphine at concentrations of $10^{-7} \mathrm{M}(P<0.01), 10^{-9} \mathrm{M}, 10^{-11} \mathrm{M}$ significantly decreased the IL-8 expression in U87 astrocytoma cell lines by $29 \%(P<0.01), 47 \%(P<0.01)$, and $68 \%(P<0.05)$, respectively (Figure 2$)$, suggesting that morphine acts as a cofactor for the HIV infection leading to a significant down-regulation of IL-8 gene expression in a dose-dependent manner. Similarly, morphine suppressed IL8 gene expression in primary astrocyte cultures [47]. Further, treatment of U87 cell lines and human astrocyte cultures with morphine for $24 \mathrm{~h}$ significantly inhibited the synthesis and secretion of IL-8 protein [47]. Down regulation of IL8 by morphine was completely blocked by the $\mu$ receptor antagonist, $\beta$-funaltrexamine suggesting that the suppression of IL-8 is mediated through this opioid receptor.

Previous studies show that morphine also modulates the expression of other cytokines such as IL-6, IL- $1 \beta$, and TNF- $\alpha$ during HIV infection. $[9,59]$. IL-6 and IL- $1 \beta$, expression was twice higher in HIV Tat and morphinetreated BV2 microglial cells (40-fold) as compared to the Tat-only-treated cells (20-fold). Similarly, TNF- $\alpha$ expression was at least twofold greater in the HIV Tat- and morphinetreated cells than those treated with Tat alone suggesting that morphine exacerbates the cytokine expression. Consistent with these results Bhokari et al. have reported similar changes in the cytokine expression associated with primary mouse microglial cultures [9]. In addition to these cytokines, an increased expression of IL-12 has been reported in astrocytes upon HIV and morphine exposure; however the increase in the IL-12 was not as prominent and as consistent as the other cytokines [59]. In another study, HIV Tat has been shown to potentiate the release of neuroactive cytokines in microglial cells [60]. Studies of El-Hage et al. [50] have further identified that the combined effects of HIV and morphine are modulated by the activation of the transcription factor NF- $\kappa \mathrm{B}$ which in turn is mediated by elevated intracellular calcium levels. Consistent with these results HIV Tat and morphine together increased $\mathrm{IkB} \alpha$ phosphorylation and induced p65 translocation into the nucleus. Interestingly, one study has demonstrated that the cotreatment with morphine significantly inhibited Tatinduced cytokine production in N9 murine microglial cells suggesting the immunosuppressive role of morphine [61]. The reason for a decrease in the IL- 8 and an increase in other cytokines like TNF- $\alpha$, IL-6, and IL- $1 \beta$ is not clear. Detailed studies may be warranted to delineate these differential effects.

\section{Morphine Decreases the $\beta$-Chemokine Expression in Astrocytes}

Chemokines have taken a central focus in the recent years mainly due to the fact that they possess inhibitory effects on HIV infection $[62,63]$. Chemokines represent small proteins of 5-12 kDA in size that are known to act as chemoattractants for NK cells, T cells, monocytes, neutrophils, fibroblasts, and endothelial cells. They are important mediators of transmigration of leucocytes across the $\mathrm{BBB}$ and play a significant role in the neuropathogenesis of HAND since these molecules recruit and regulate the movement of inflammatory cells into the CNS. Further, chemokines also regulate the degree of HIV infection $[64,65]$. Deregulation in chemokine expression is a common phenomenon that is associated with astrocytes, microglia, macrophages, neurons, and endothelial cells exposed to virus, viral proteins and also in HIV dementia patients [66-69]. MIP-1 $\beta$, also known as macrophage inflammatory protein has been reported to block CCR5 and CCR3 receptors [58, 70, 71]. Studies from our laboratory have shown that astrocytes treated with morphine at concentrations $10^{-7} \mathrm{M}, 10^{-9} \mathrm{M}, 10^{-11} \mathrm{M}$ for a period of $48 \mathrm{~h}$ significantly inhibited the protective gene MIP- $1 \beta$ expression by $78 \%, 65 \%$, and $43 \%$, respectively [49]. Monocyte chemoattractant protein (MCP)-1 is another CC-chemokine ligand (CCL2) that is particularly important in HIV neuropathogenesis in part because it mediates mononuclear phagocytes and leukocytes migration into the brain $[66,67]$. Lines of evidence have indicated that the levels of CCL2 (MCP-1) and the CCR2 receptor levels very well correlate with the neurocognitive defects accompanying the neuropathogenesis of HIV disease progression [72, 73]. Earlier studies have shown that exposure of astrocytes with HIV-Tat and morphine together result in a synergistic increase in the release of the CCL2; however such synergism was lacking in the microglial cells [59]. Constitutively expressed CCL2 mRNA was significantly upregulated in 


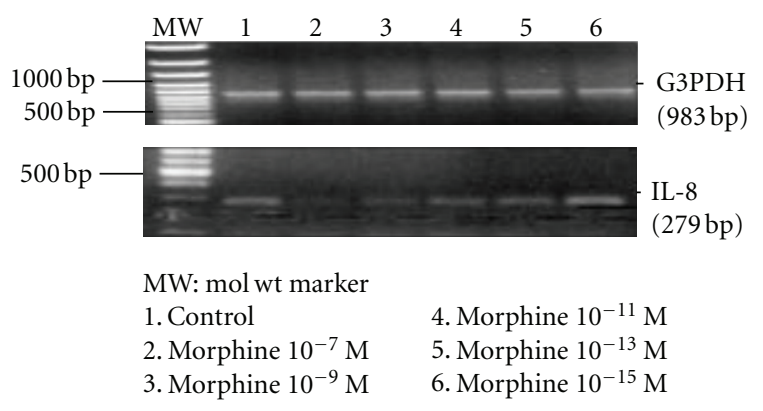

(a)

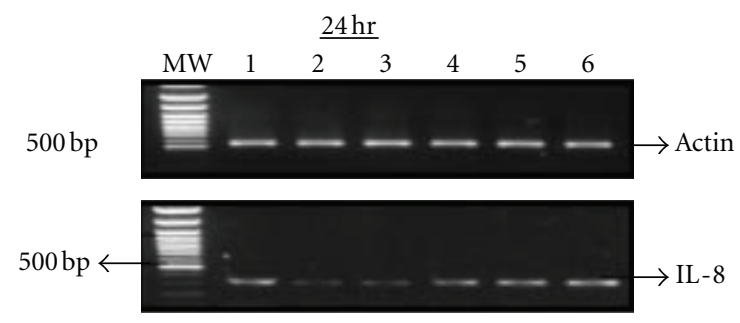

(c)

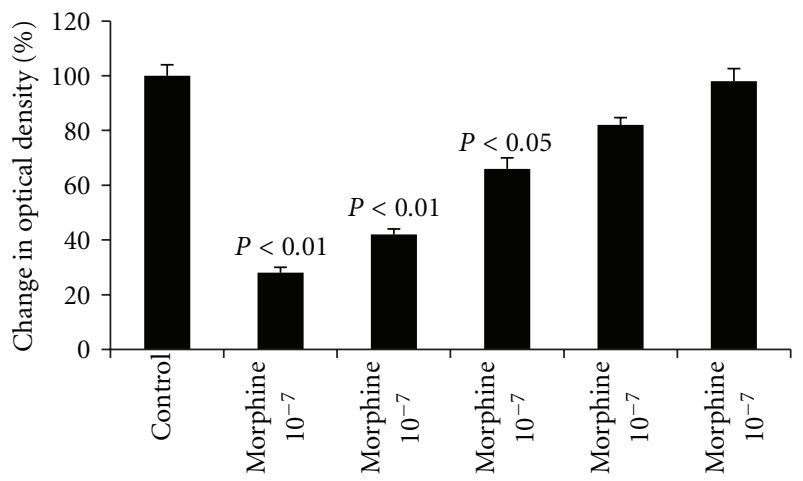

(b)

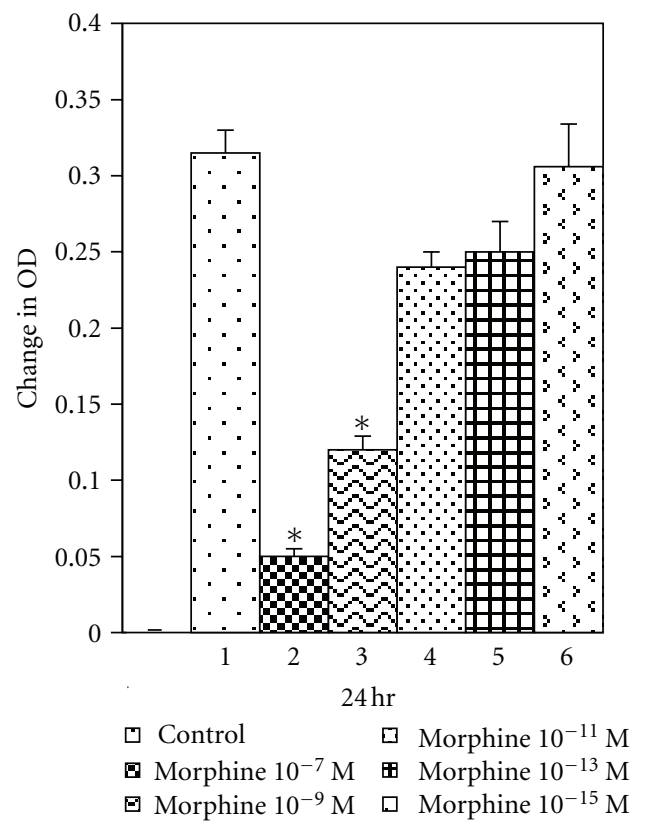

(d)

FIGURE 2: Morphine inhibits IL-8 gene expression in astrocytes and U87 astrocytoma cells. $3 \times 10^{6}$ cells were cultured and treated with or without morphine for $24 \mathrm{~h}$. RNA was extracted, reverse-transcribed, and amplified by PCR using primers for IL- 8 and housekeeping gene G3PDH. PCR products were resolved on 1.2\% agarose gel by electrophoresis. G3PDH remained unchanged at all periods while morphine significantly suppressed the expression of IL-8 gene in a dose-dependent manner in U87 astrocytoma (a). Quantitation of the effect of morphine on IL-8 gene expression by densitometry in U87 cells after normalizing to housekeeping gene (b). Kinetics of morphine inhibition of IL-8 gene expression in human astrocytes treated with different doses of morphine for $24 \mathrm{~h}$ (c). Quantitation of the effect of morphine on IL-8 gene expression in astrocyte cultures by densitometry after normalizing to housekeeping gene (d). This figure is reproduced from the original article in Journal of Immunology, 169: 3589-99, Mahajan et al. [47]. Morphine regulates gene expression of alpha- and betachemokines and their receptors on astroglial cells via the opioid mu receptor. Copyright 2002. The American Association of Immunologists.

human neurons by morphine exposure in a concentration and time-dependent manner but not in human astrocytes and microglia cells even though microglia and astrocytes also constitutively express CCL2 [74]. A $\mu$ opioid receptor agonist [D-Ala2, N-Me-Phe4, Glyol5] enkephalin (DAMGO) was shown to increase the expression of proinflammatory chemokines like CCL2, CCL5, and CXCL10 in PHAstimulated human PBMCs at both protein and mRNA levels [75]. Increased CCL2 in astrocytes near the area of HIV Tat injection following the systemic administration of morphine indicates the role of morphine in enhancing inflammatory responses [48]. Consistent with these reports, it has been shown that glial activation and inflammation was attenuated completely in the CCR2 knockout mice compared to the wild type after the Tat and morphine injection either alone or together [76]. In addition to CCL2, CCL5, and CCL3 (MIP-1 $\alpha$ ) protein and mRNA expression levels were significantly exacerbated when exposed to Tat and morphine together as compared to either of them when present alone. Further these studies indicated that the ability of morphine to enhance the Tat-induced chemokine production is mediated by $\mu$ opioid receptors [59]. 


\section{Effect of Morphine on Chemokine Receptors}

Infection of cells with HIV requires the presence of coreceptors like CCR5, CCR2b, and CCR3 in addition to $\mathrm{CD}^{+}$receptors $[58,70]$. These coreceptors are located in various cell types including brain cells [77]. It is possible that chemokines bind to more than one specific receptor. Mip- $1 \beta$ binds to CCR5 and CCR3 while MCP- 1 binds to the CCR2b receptor. Both chemokines and their receptors have been demonstrated to play important roles in the neuropathogenesis of HIV infection. These receptors have also been shown to be present in higher levels in autopsied brain samples obtained from AIDS patients and have been shown to act as coreceptors for HIV infection [78-83].

CC-chemokine ligand 5 (CCL5) also known as RANTES specifically attracts and aids in the migration of the mononuclear macrophages and leukocytes to the site of infection [85]. CCL5 is known to preferentially stimulate an important HIV-receptor CCR5. Activation of CCR5 regulates the pathogenesis of HIV and simian immunodeficiency virus infection [86-88]. El-Hage et al. [59] have reported an increase in the CCL5 in HIV Tat-exposed astrocytes. In addition, morphine increases the CCR5 expression in astrocytes [49]. Further, the inflammatory and toxic effects of Tat and morphine together were attenuated in CCL5 null mice [86]. Our studies have demonstrated a dosedependent increase in HIV-1 coreceptors CCR2b, CCR3, and CCR5 in astrocytes treated with morphine [49] (Figure 3(a)). Further, the addition of opioid receptor antagonists, naloxone $\beta$-funaltrexamine, to astrocyte cultures reversed the morphine-induced effects suggesting that the morphinemediated effects were via $\mu$ opioid receptor [49]. Mahajan et al. have also shown that HIV-1 gp120-induced chemokine receptor expression is exacerbated by morphine in U773 astrocytoma cell lines [84]. Studies by other investigators have also confirmed the finding that morphine enhances HIV infection by significantly upregulating CCR5 and such increase was associated with inhibition of the endogenous production of beta chemokines in human mononuclear phagocytes [89]. In addition to these studies, morphine has been shown to upregulate CCR5 in $\mathrm{CD}^{+}$lymphoblasts and $\mathrm{CD}_{14}{ }^{+}$monocytes [90]. In another study, Bokhari and colleagues have demonstrated the upregulation of the CCR5 in the murine microglia when treated with morphine and such effect was abolished by treatment with an opioid receptor antagonist naloxone [9]. Together these studies indicate that morphine plays a positive role as a cofactor in the neuropathogenesis of HAND.

\section{Signal Transduction Mechanisms That Mediate-Morphine-Induced Effects in HIV-1}

Changes in the expression of chemokines and their receptors can lead to signaling events that regulate various biological responses such as increased calcium influx and mitogenactivated protein kinase (MAPK) activation. Endogenous opioid peptides and agonists of opioid drugs have the potential to activate various signaling cascades either by suppressing adenyl cyclase, cation channels, or MAPK pathways [91]. Studies from our laboratory have shown that morphine increases p38 MAPK and down-regulates cAMP response element binding (CREB) gene and protein expression in U87 astrocytes [49] (Figures 3(b) and 3(c)). Consistent with these studies, other investigators have identified the involvement of various mitogen-activated kinases in morphine-mediated toxicity $[92,93]$. Stimulation of MAPKs has been shown to regulate the HIV-1 infectivity [94-96]. Binding of morphine to the $\mu$ opioid receptor stimulates G-protein-associated molecules thereby inhibiting cAMP and resulting in lowered phosphorylation of CREB [91]. CREB mediated transcription is an important factor in neuronal adaptive response and has been demonstrated to be vital for normal neurocognitive functioning [9799]. Increased phosphorylation of ERK1/2, JNK, p38, and Akt in a time-dependent manner has been reported in human brain microvascular endothelial cells when exposed to morphine [100]. In another study using human neurons, Malik et al. showed that the synergistic effects of HIV Tat and morphine involve JNK and ERK1/2 pathways; however, there were no changes in the p38 activation [44]. Chronic treatment of activated $\mathrm{T}$ cells with morphine inhibited the phosphorylation and activation of ERK1/2 and p38 MAPK further leading to a downregulation of the transcription factors activator protein-1 (AP-1), nuclear factor of activated cells (NFAT) and NF $\kappa B$ [101].

Platelet-derived growth factor has been reported to be a mitogen and chemoattractant for different types of cells in vivo and in vitro and have the ability to induce the production of cytokines [102-104]. PDGF has been identified to be expressed at a higher level in the brain of macaques with SIV encephalitis [105]. Recent reports have demonstrated that human brain microvascular endothelial cells (HBMECs) exposed to morphine show increased PDGF mRNA as well as protein expression, leading to the activation of its downstream target transcription factor, namely, early growth response-1(Egr-1) [100]. The activation of both PDGF and Egr-1 was blocked by using specific inhibitors for ERK, JNK, and P38 indicating the role of MAP kinases in the PDGF activation [100]. Further, blockade of the $\mu$ opioid receptor by its antagonist naloxone significantly reduced the upregulation of both PDGF and Egr-1 suggesting that these events are mediated through the opioid receptor. The studies of Wen et al. further show that morphine activates Akt pathway; however this molecule does not mediate the activation of either PDGF or Egr-1 [100]. Activation of PDGF has been reported to be involved in BBB damage. Down regulation of ZO-1, a tight junction protein by morphine, has also been reported to be mediated by the $\mu$ opioid receptor and PDGF $[106,107]$.

\section{Conclusions}

These studies suggest that the drugs of abuse such as morphine enhance HIV-1 replication and infectivity in various cell types such as PBMCs and CNS cells. The mechanisms involved in such effects may be mediated by altering HIV-1 coreceptors and chemokines. The ability of opioids to alter the expression of chemokines and chemokine 


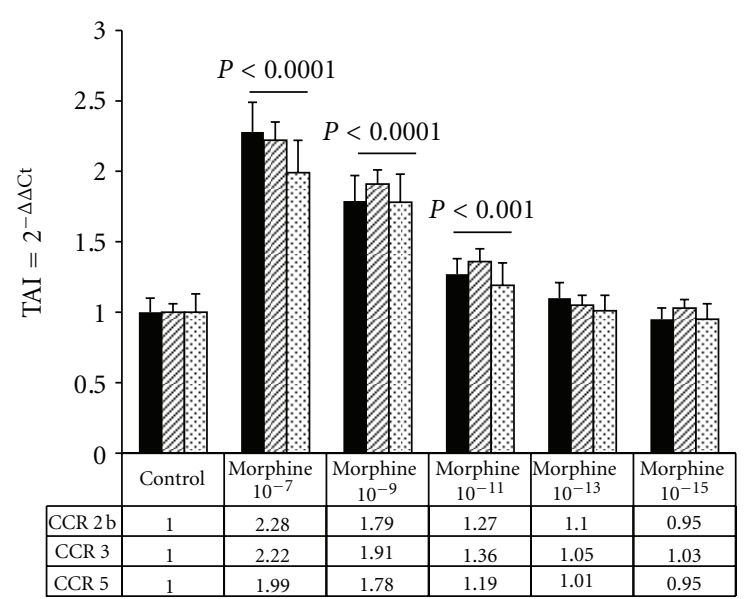

CCR2b

$\square$ CCR3 ब CCR5

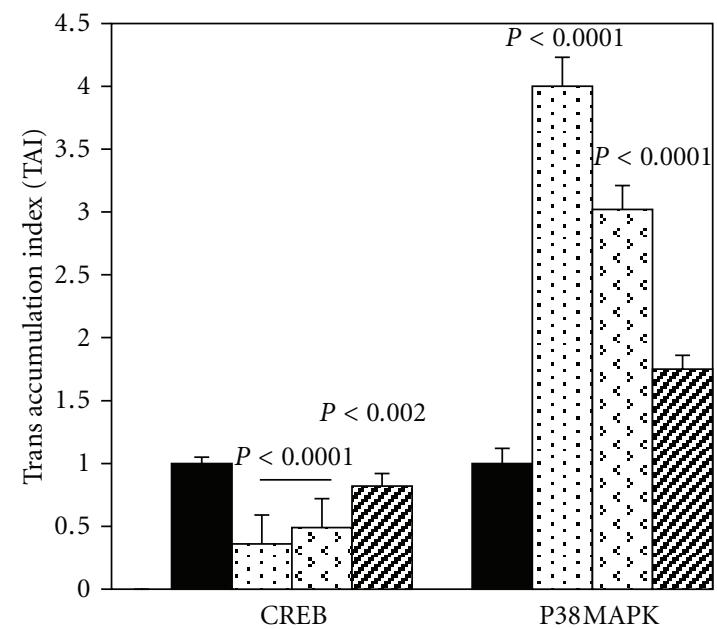

Control $10^{-7} \mathrm{M} \quad$ Morphine $10^{-9} \mathrm{M}$

(b)

(a)

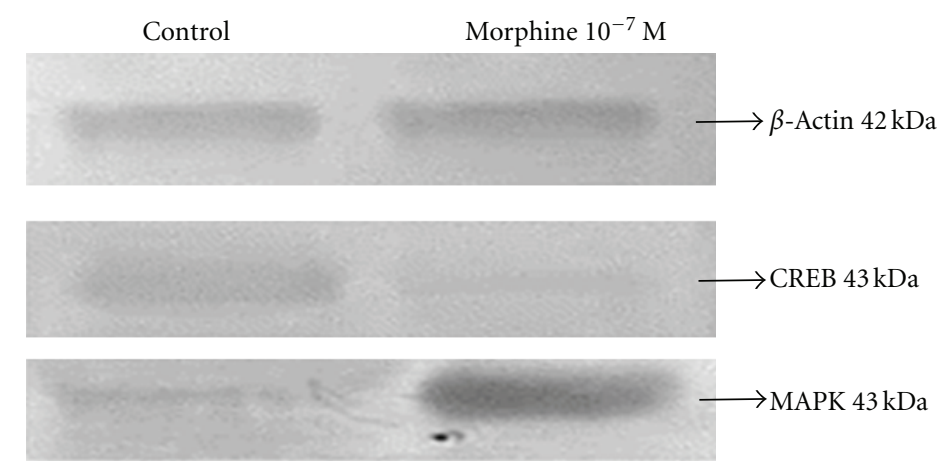

(c)

FIGURE 3: Morphine enhances the expression of CCR2b, CCR5, and CCR3 genes in human astrocytes (a). Astrocyte cultures were treated with different concentrations of morphine for $48 \mathrm{~h}$ and the relative expression of the mRNA was determined by real-time PCR. Morphine significantly upregulated p38 MAPK and downregulated CREB gene (b) and protein expression in astrocytes (c). This figure is reproduced from Clinical Immunology, 115: 323-32, Mahajan et al. [49, 84]. Morphine modulates chemokine gene regulation in normal human astrocytes. Copyright 2005, with permission from Elsevier.

receptors by various cells of the central nervous system may significantly enhance the ability of HIV to infect the brain. Morphine also alters the status of both pro- and antiapoptotic molecules finally leading to a higher rate of apoptosis which is further exacerbated in case of HIV infection and such events are mediated by various signaling mechanisms. Overall, HIV infection in the brain may be enhanced either by viral binding and cellular uptake by upregulating HIV coreceptors or chemokine expression. Together, these studies provide important information on the molecular aspects of morphine, HIV-1 infection, and HIV pathogenesis, which may help in developing novel antiHIV strategies targeting the coreceptors and chemokines.

\section{Conflict of Interests}

There are no conflicts of interest for any of the authors.

\section{Acknowledgments}

The authors thank Dr. Marisela Agudelo and Dr. Venkata Atluri for their careful and critical reading of the paper. This study was supported by the Grants from National Institute of Health (NIH) R37DA025576 and RO1MH085259.

\section{References}

[1] A. Antinori, G. Arendt, J. T. Becker et al., "Updated research nosology for HIV-associated neurocognitive disorders," Neurology, vol. 69, no. 18, pp. 1789-1799, 2007.

[2] K. Goodkin, F. L. Wilkie, M. Concha et al., "Aging and neuro-AIDS conditions and the changing spectrum of HIV1-associated morbidity and mortality," Journal of Clinical Epidemiology, vol. 54, no. 12, supplement 1, pp. S35-S43, 2001. 
[3] J. C. McArthur, D. R. Hoover, H. Bacellar et al., "Dementia in AIDS patients: incidence and risk factors. multicenter AIDS Cohort Study," Neurology, vol. 43, pp. 2245-2252, 1993.

[4] M. Mintz, "Clinical comparison of adult and pediatric NeuroAIDS," Advances in Neuroimmunology, vol. 4, no. 3, pp. 207-221, 1994.

[5] K. R. Robertson and C. D. Hall, "Human immunodeficiency virus-related cognitive impairment and the acquired immunodeficiency syndrome dementia complex," Seminars in Neurology, vol. 12, no. 1, pp. 18-27, 1992.

[6] J. Zheng and H. E. Gendelman, "The HIV-1 associated dementia complex: a metabolic encephalopathy fueled by viral replication in mononuclear phagocytes," Current Opinion in Neurology, vol. 10, no. 4, pp. 319-325, 1997.

[7] C. Beyrer, M. H. Razak, K. Lisam, J. Chen, W. Lui, and X. F. Yu, "Overland heroin trafficking routes and HIV-1 spread in south and south-east Asia," AIDS, vol. 14, no. 1, pp. 75-83, 2000.

[8] S. M. Bokhari, R. Hegde, S. Callen et al., "Morphine potentiates neuropathogenesis of SIV infection in Rhesus Macaques," Journal of Neuroimmune Pharmacology, pp. 1-14, 2011.

[9] S. M. Bokhari, H. Yao, C. Bethel-Brown et al., "Morphine enhances Tat-induced activation in murine microGlia," Journal of NeuroVirology, vol. 15, no. 3, pp. 219-228, 2009.

[10] R. M. Donahoe, "Multiple ways that drug abuse might influence AIDS progression: clues from a monkey model," Journal of Neuroimmunology, vol. 147, no. 1-2, pp. 28-32, 2004.

[11] H. Francis, "Substance abuse and HIV infection," Topics in HIV Medicine, vol. 11, no. 1, pp. 20-24, 2003.

[12] F. Kapadia, D. Vlahov, R. M. Donahoe, and G. Friedland, "The role of substance abuse in HIV disease progression: reconciling differences from laboratory and epidemiologic investigations," Clinical Infectious Diseases, vol. 41, no. 7, pp. 1027-1034, 2005.

[13] M. Vaswani and N. G. Desai, "HIV infection and high-risk behaviors in opioid dependent patients: the Indian context," Addictive Behaviors, vol. 29, no. 8, pp. 1699-1705, 2004.

[14] J. E. Bell, I. C. Anthony, and P. Simmonds, "Impact of HIV on regional \& cellular organization of the brain," Current HIV Research, vol. 4, no. 3, pp. 249-257, 2006.

[15] J. E. Bell, R. P. Brettle, A. Chiswick, and P. Simmonds, "HIV encephalitis, proviral load and dementia in drug users and homosexuals with AIDS. Effect of neocortical involvement," Brain, vol. 121, no. 11, pp. 2043-2052, 1998.

[16] A. Nath, W. F. Maragos, M. J. Avison, F. A. Schmitt, and J. R. Berger, "Acceleration of HIV dementia with methamphetamine and cocaine," Journal of NeuroVirology, vol. 7, no. 1, pp. 66-71, 2001.

[17] R. Ellis, D. Langford, and E. Masliah, "HIV and antiretroviral therapy in the brain: neuronal injury and repair," Nature Reviews Neuroscience, vol. 8, no. 1, pp. 33-44, 2007.

[18] J. C. McArthur and B. J. Brew, "HIV-associated neurocognitive disorders: is there a hidden epidemic?" AIDS, vol. 24, no. 9, pp. 1367-1370, 2010.

[19] A. Nath, K. F. Hauser, V. Wojna et al., "Molecular basis for interactions of HIV and drugs of abuse," Journal of Acquired Immune Deficiency Syndromes, vol. 31, supplement 2, pp. S62-S69, 2002.

[20] T. K. Eisenstein and M. E. Hilburger, "Opioid modulation of immune responses: effects on phagocyte and lymphoid cell populations," Journal of Neuroimmunology, vol. 83, no. 1-2, pp. 36-44, 1998.
[21] D. Messmer, I. Hatsukari, N. Hitosugi, I. G. H. Schmidt-Wolf, and P. C. Singhal, "Morphine reciprocally regulates IL-10 and IL-12 production by monocyte-derived human dendritic cells and enhances T cell activation," Molecular Medicine, vol. 12, no. 11-12, pp. 284-290, 2006.

[22] V. Rivera-Amill, P. S. Silverstein, R. J. Noel, S. Kumar, and A. Kumar, "Morphine and rapid disease progression in nonhuman primate model of AIDS: inverse correlation between disease progression and virus evolution," Journal of Neuroimmune Pharmacology, vol. 5, no. 1, pp. 122-132, 2010.

[23] T. B. Saurer, K. A. Carrigan, S. G. Ijames, and D. T. Lysle, "Suppression of natural killer cell activity by morphine is mediated by the nucleus accumbens shell," Journal of Neuroimmunology, vol. 173, no. 1-2, pp. 3-11, 2006.

[24] J. Wang, R. A. Barke, J. Ma, R. Charboneau, and S. Roy, "Opiate abuse, innate immunity, and bacterial infectious diseases," Archivum Immunologiae et Therapia Experimentalis (Warsz), vol. 56, pp. 299-309, 2008.

[25] K. F. Hauser, N. El-Hage, S. Buch et al., "Molecular targets of opiate drug abuse in neuroAIDS," Neurotoxicity Research, vol. 8, no. 1-2, pp. 63-80, 2005.

[26] A. Nath, C. Anderson, M. Jones et al., "Neurotoxicity and dysfunction of dopaminergic systems associated with AIDS dementia," Journal of Psychopharmacology, vol. 14, no. 3, pp. 222-227, 2000.

[27] F. Dronda, J. Zamora, S. Moreno et al., "CD4 cell recovery during successful antiretroviral therapy in naive HIVinfected patients: the role of intravenous drug use," AIDS, vol. 18, no. 16, pp. 2210-2212, 2004.

[28] R. Kumar, C. Torres, Y. Yamamura et al., "Modulation by morphine of viral set point in rhesus macaques infected with simian immunodeficiency virus and simian-human immunodeficiency virus," Journal of Virology, vol. 78, no. 20, pp. 11425-11428, 2004.

[29] N. K. Banda, J. Bernier, D. K. Kurahara et al., "Crosslinking CD4 by human immunodeficiency virus gp 120 primes T cells for activation-induced apoptosis," Journal of Experimental Medicine, vol. 176, no. 4, pp. 1099-1106, 1992.

[30] M. L. Gougeon and L. Montagnier, "Apoptosis in AIDS," Science, vol. 260, no. 5112, pp. 1269-1270, 1993.

[31] C. J. Li, D. J. Friedman, C. Wang, V. Metelev, and A. B. Pardee, "Induction of apoptosis in uninfected lymphocytes by HIV-1 Tat protein," Science, vol. 268, no. 5209, pp. 429-431, 1995.

[32] Y. Y. Lu, Y. Koga, K. Tanaka, M. Sasaki, G. Kimura, and K. Nomoto, "Apoptosis induced in $\mathrm{CD}^{+}$cells expressing gp160 of human immunodeficiency virus type 1," Journal of Virology, vol. 68, no. 1, pp. 390-399, 1994.

[33] P. K. Peterson, G. Gekker, S. Hu et al., "Morphine amplifies HIV-1 expression in chronically infected promonocytes cocultured with human brain cells," Journal of Neuroimmunology, vol. 50, no. 2, pp. 167-175, 1994.

[34] P. K. Peterson, G. Gekker, R. Schut, S. Hu, H. H. Balfour, and C. C. Chao, "Enhancement of HIV-1 replication by opiates and cocaine: the cytokine connection," Advances in Experimental Medicine and Biology, vol. 335, pp. 181-188, 1993.

[35] M. P. N. Nair, S. A. Schwartz, R. Polasani, J. Hou, A. Sweet, and K. C. Chadha, "Immunoregulatory effects of morphine on human lymphocytes," Clinical and Diagnostic Laboratory Immunology, vol. 4, no. 2, pp. 127-132, 1997.

[36] J. Moorman, Y. Zhang, B. Liu et al., "HIV-1 gp120 primes lymphocytes for opioid-induced, beta-arrestin 2-dependent apoptosis," Biochimica et Biophysica Acta, vol. 1793, pp. 1366-1371, 2009. 
[37] M. Rojavin, I. Szabo, J. L. Bussiere, T. J. Rogers, M. W. Adler, and T. K. Eisenstein, "Morphine treatment in vitro or in vivo decreases phagocytic functions of murine macrophages," Life Sciences, vol. 53, no. 12, pp. 997-1006, 1993.

[38] N. Zhang and J. J. Oppenheim, "Crosstalk between chemokines and neuronal receptors bridges immune and nervous systems," Journal of Leukocyte Biology, vol. 78, no. 6, pp. 1210-1214, 2005.

[39] J. A. Beltran, A. Pallur, and S. L. Chang, "HIV-1 gp120 upregulation of the mu opioid receptor in TPA-differentiated HL-60 cells," International Immunopharmacology, vol. 6, no. 9, pp. 1459-1467, 2006.

[40] P. K. Peterson, G. Gekker, J. R. Lokensgard et al., “ $\kappa$-opioid receptor agonist suppression of HIV-1 expression in CD4+ lymphocytes," Biochemical Pharmacology, vol. 61, no. 9, pp. 1145-1151, 2001.

[41] J. R. Lokensgard, G. Gekker, and P. K. Peterson, “ $\kappa$-Opioid receptor agonist inhibition of $\mathrm{HIV}-1$ envelope glycoproteinmediated membrane fusion and CXCR4 expression on CD4+ lymphocytes," Biochemical Pharmacology, vol. 63, no. 6, pp. 1037-1041, 2002.

[42] K. F. Hauser, Y. K. Hahn, V. V. Adjan et al., "HIV-1 tat and morphine have interactive effects on oligodendrocyte survival and morphology," Glia, vol. 57, no. 2, pp. 194-206, 2009.

[43] S. Hu, W. S. Sheng, J. R. Lokensgard, and P. K. Peterson, "Morphine potentiates HIV-1 gp120-induced neuronal apoptosis," Journal of Infectious Diseases, vol. 191, no. 6, pp. 886-889, 2005.

[44] S. Malik, H. Khalique, S. Buch, and P. Seth, "A growth factor attenuates HIV-1 Tat and morphine induced damage to human neurons: implication in HIV/AIDS-drug abuse cases," PLoS ONE, vol. 6, no. 3, Article ID e18116, 2011.

[45] M. Kaul, G. A. Garden, and S. A. Lipton, "Pathways to neuronal injury and apoptosis in HIV-associated dementia," Nature, vol. 410, no. 6831, pp. 988-994, 2001.

[46] J. A. Gurwell, A. Nath, Q. Sun et al., "Synergistic neurotoxicity of opioids and human immunodeficiency virus-1 Tat protein in striatal neurons in vitro," Neuroscience, vol. 102, no. 3, pp. 555-563, 2001.

[47] S. D. Mahajan, S. A. Schwartz, T. C. Shanahan, R. P. Chawda, and M. P. Nair, "Morphine regulates gene expression of alpha- and beta-chemokines and their receptors on astroGlial cells via the opioid mu receptor," The Journal of Immunology, vol. 169, pp. 3589-3599, 2002.

[48] N. El-Hage, G. Wu, J. Wang et al., "HIV-1 Tat and opiate-induced changes in astrocytes promote chemotaxis of microGlia through the expression of MCP-1 and alternative chemokines," Glia, vol. 53, no. 2, pp. 132-146, 2006.

[49] S. D. Mahajan, S. A. Schwartz, R. Aalinkeel, R. P. Chawda, D. E. Sykes, and M. P. N. Nair, "Morphine modulates chemokine gene regulation in normal human astrocytes," Clinical Immunology, vol. 115, no. 3, pp. 323-332, 2005.

[50] N. El-Hage, A. J. Bruce-Keller, T. Yakovleva et al., "Morphine exacerbates HIV-1 Tat-induced cytokine production in astrocytes through convergent effects on $[\mathrm{Ca} 2+] \mathrm{i}$, NF$\kappa \mathrm{B}$ trafficking and transcription," PLoS ONE, vol. 3, no. 12, Article ID e4093, 2008.

[51] Y. Dong and E. N. Benveniste, "Immune function of astrocytes," Glia, vol. 36, no. 2, pp. 180-190, 2001.

[52] S. M. Allan and N. J. Rothwell, "Inflammation in central nervous system injury," Philosophical Transactions of the Royal Society B, vol. 358, no. 1438, pp. 1669-1677, 2003.
[53] A. Rahman, K. Harvey, and R. A. Siddiqui, "Interleukin-8: an autocrine inflammatory mediator," Current Pharmaceutical Design, vol. 5, no. 4, pp. 241-253, 1999.

[54] M. Baggiolini and I. Clark-Lewis, "Interleukin-8, a chemotactic and inflammatory cytokine," FEBS Letters, vol. 307, no. 1, pp. 97-101, 1992.

[55] A. Shah and A. Kumar, "HIV-1 gp120-mediated increases in IL-8 production in astrocytes are mediated through the NF$\kappa \mathrm{B}$ pathway and can be silenced by gp120-specific siRNA," Journal of Neuroinflammation, vol. 7, article 96, 2010.

[56] E. R. Sherwood and D. S. Prough, "Interleukin-8, neuroinflammation, and secondary brain injury," Critical Care Medicine, vol. 28, no. 4, pp. 1221-1223, 2000.

[57] S. Meddows-Taylor, D. J. Martin, and C. T. Tiemessen, "Reduced expression of interleukin-8 receptors A and B on polymorphonuclear neutrophils from persons with human immunodeficiency virus type 1 disease and pulmonary tuberculosis," Journal of Infectious Diseases, vol. 177, no. 4, pp. 921-930, 1998.

[58] T. S. Stantchev and C. C. Broder, "Human immunodeficiency virus type-1 and chemokines: beyond competition for common cellular receptors," Cytokine and Growth Factor Reviews, vol. 12, no. 2-3, pp. 219-243, 2001.

[59] N. El-Hage, J. A. Gurwell, I. N. Singh, P. E. Knapp, A. Nath, and K. F. Hauser, "Synergistic increases in intracellular $\mathrm{Ca}^{2+}$, and the release of MCP-1, RANTES, and IL- 6 by astrocytes treated with opiates and HIV-1 tat," Glia, vol. 50, no. 2, pp. 91-106, 2005.

[60] A. J. Bruce-Keller, S. W. Barger, N. I. Moss, J. T. Pham, J. N. Keller, and A. Nath, "Pro-inflammatory and pro-oxidant properties of the HIV protein Tat in a microGlial cell line: attenuation by $17 \beta$-estradiol," Journal of Neurochemistry, vol. 78, no. 6, pp. 1315-1324, 2001.

[61] J. Turchan-Cholewo, F. O. Dimayuga, S. Gupta et al., "Morphine and HIV-Tat increase microGlial-free radical production and oxidative stress: possible role in cytokine regulation," Journal of Neurochemistry, vol. 108, no. 1, pp. 202-215, 2009.

[62] P. Lusso, "HIV and chemokines: implications for therapy and vaccine," Vaccine, vol. 20, no. 15, pp. 1964-1967, 2002.

[63] A. Verani and P. Lusso, "Chemokines as natural HIV antagonists," Current Molecular Medicine, vol. 2, no. 8, pp. 691-702, 2002.

[64] V. C. Asensio and L. L. Campbell, "Chemokines and viral diseases of the central nervous system," Advances in Virus Research, vol. 56, pp. 127-173, 2001.

[65] M. E. Dorf, M. A. Berman, S. Tanabe, M. Heesen, and Y. Luo, "Astrocytes express functional chemokine receptors," Journal of Neuroimmunology, vol. 111, no. 1-2, pp. 109-121, 2000.

[66] K. Conant, A. Garzino-Demo, A. Nath et al., "Induction of monocyte chemoattractant protein-1 in HIV-1 Tatstimulated astrocytes and elevation in AIDS dementia," Proceedings of the National Academy of Sciences of the United States of America, vol. 95, no. 6, pp. 3117-3121, 1998.

[67] E. A. Eugenin, K. Osiecki, L. Lopez, H. Goldstein, T. M. Calderon, and J. W. Berman, "CCL2/monocyte chemoattractant protein-1 mediates enhanced transmigration of human immunodeficiency virus (HIV)-infected leukocytes across the blood-brain barrier: a potential mechanism of HIV-CNS invasion and NeuroAIDS," Journal of Neuroscience, vol. 26, no. 4, pp. 1098-1106, 2006.

[68] W. Kelder, J. C. McArthur, T. Nance-Sproson, D. McClernon, and D. E. Griffin, " $\beta$-Chemokines MCP-1 and RANTES 
are selectively increased in cerebrospinal fluid of patients with human immunodeficiency virus-associated dementia," Annals of Neurology, vol. 44, no. 5, pp. 831-835, 1998.

[69] C. M. McManus, K. Weidenheim, S. E. Woodman et al., "Chemokine and chemokine-receptor expression in human Glial elements: induction by the HIV protein, Tat, and chemokine autoregulation," American Journal of Pathology, vol. 156, no. 4, pp. 1441-1453, 2000.

[70] T. Lehner, "The role of CCR5 chemokine ligands and antibodies to CCR5 coreceptors in preventing HIV infection," Trends in Immunology, vol. 23, no. 7, pp. 347-351, 2002.

[71] T. Murakami and N. Yamamoto, "Roles of chemokines and chemokine receptors in HIV-1 infection," International Journal of Hematology, vol. 72, no. 4, pp. 412-417, 2000.

[72] J. L. Mankowski, S. E. Queen, J. E. Clements, and M. C. Zink, "Cerebrospinal fluid markers that predict SIV CNS disease," Journal of Neuroimmunology, vol. 157, no. 1-2, pp. 66-70, 2004.

[73] J. J. Sevigny, S. M. Albert, M. P. McDermott et al., "Evaluation of HIV RNA and markers of immune activation as predictors of HIV-associated dementia," Neurology, vol. 63, no. 11, pp. 2084-2090, 2004.

[74] R. B. Rock, S. Hu, W. S. Sheng, and P. K. Peterson, "Morphine stimulates CCL2 production by human neurons," Journal of Neuroinflammation, vol. 3, article 32, 2006.

[75] M. A. Wetzel, A. D. Steele, T. K. Eisenstein, M. W. Adler, E. E. Henderson, and T. J. Rogers, " $\mu$-Opioid induction of monocyte chemoattractant protein-1, RANTES, and IFN- $\gamma$ inducible protein-10 expression in human peripheral blood mononuclear cells," Journal of Immunology, vol. 165, no. 11, pp. 6519-6524, 2000.

[76] N. El-Hage, G. Wu, J. Ambati, A. J. Bruce-Keller, P. E. Knapp, and K. F. Hauser, "CCR2 mediates increases in Glial activation caused by exposure to HIV-1 Tat and opiates," Journal of Neuroimmunology, vol. 178, no. 1-2, pp. 9-16, 2006.

[77] R. Vallejo, O. de Leon-Casasola, and R. Benyamin, "Opioid therapy and immunosuppression: a review," American Journal of Therapeutics, vol. 11, no. 5, pp. 354-365, 2004.

[78] R. C. Gallo, A. Garzino-Demo, and A. L. DeVico, "HIV infection and pathogenesis: what about chemokines?" Journal of Clinical Immunology, vol. 19, no. 5, pp. 293-299, 1999.

[79] A. Garzino-Demo, A. L. DeVico, F. Cocchi, and R. C. Gallo, "Beta-chemokines and protection from HIV type 1 disease," AIDS Research and Human Retroviruses, vol. 14, pp. S177S184, 1998.

[80] A. Garzino-Demo, A. L. Devico, and R. C. Gallo, "Chemokine receptors and chemokines in HIV infection," Journal of Clinical Immunology, vol. 18, no. 4, pp. 243-255, 1998.

[81] O. M. Howard, J. J. Oppenheim, and J. M. Wang, "Chemokines as molecular targets for therapeutic intervention," Journal of Clinical Immunology, vol. 19, no. 5, pp. 280 292, 1999.

[82] A. Kinter, J. Arthos, C. Cicala, and A. S. Fauci, "Chemokines, cytokines and HIV: a complex network of interactions that influence HIV pathogenesis," Immunological Reviews, vol. 177, pp. 88-98, 2000.

[83] T. E. Lane, V. C. Asensio, N. Yu, A. D. Paoletti, I. L. Campbell, and M. J. Buchmeier, "Dynamic regulation of alpha- and beta-chemokine expression in the central nervous system during mouse hepatitis virus-induced demyelinating disease," The Journal of Immunology, vol. 160, pp. 970-978, 1998.
[84] S. D. Mahajan, R. Aalinkeel, J. L. Reynolds et al., "Morphine exacerbates HIV-1 viral protein gp120 induced modulation of chemokine gene expression in U373 astrocytoma cells," Current HIV Research, vol. 3, no. 3, pp. 277-288, 2005.

[85] M. D. Miller and M. S. Krangel, "Biology and biochemistry of the chemokines: a family of chemotactic and inflammatory cytokines," Critical Reviews in Immunology, vol. 12, no. 1-2, pp. 17-46, 1992.

[86] N. El-Hage, A. J. Bruce-Keller, P. E. Knapp, and K. F. Hauser, "CCL5/RANTES gene deletion attenuates opioidinduced increases in Glial CCL2/MCP-1 immunoreactivity and activation in HIV-1 Tat-exposed mice," Journal of Neuroimmune Pharmacology, vol. 3, no. 4, pp. 275-285, 2008.

[87] R. Kitai, M. L. Zhao, N. Zhang, L. L. Hua, and S. C. Lee, "Role of MIP- $1 \beta$ and RANTES in HIV-1 infection of microGlia: inhibition of infection and induction by IFN $\beta$," Journal of Neuroimmunology, vol. 110, no. 1-2, pp. 230-239, 2000.

[88] V. G. Sasseville, M. M. Smith, C. R. Mackay et al., "Chemokine expression in simian immunodeficiency virusinduced AIDS encephalitis," American Journal of Pathology, vol. 149, no. 5, pp. 1459-1467, 1996.

[89] Y. Li, J. D. Merrill, K. Mooney et al., "Morphine enhances HIV infection of neonatal macrophages," Pediatric Research, vol. 54, no. 2, pp. 282-288, 2003.

[90] A. D. Steele, E. E. Henderson, and T. J. Rogers, " $\mu$-Opioid modulation of HIV-1 coreceptor expression and HIV-1 replication,” Virology, vol. 309, no. 1, pp. 99-107, 2003.

[91] J. S. Gutkind, "The pathways connecting G protein-coupled receptors to the nucleus through divergent mitogen-activated protein kinase cascades," The Journal of Biological Chemistry, vol. 273, no. 4, pp. 1839-1842, 1998.

[92] C. Chen, M. Farooqui, and K. Gupta, "Morphine stimulates vascular endothelial growth factor-like signaling in mouse retinal endothelial cells," Current Neurovascular Research, vol. 3, no. 3, pp. 171-180, 2006.

[93] K. Gupta, S. Kshirsagar, L. Chang et al., "Morphine stimulates angiogenesis by activating proangiogenic and survivalpromoting signaling and promotes breast tumor growth," Cancer Research, vol. 62, no. 15, pp. 4491-4498, 2002.

[94] J. M. Jacqué, A. Mann, H. Enslen et al., "Modulation of HIV-1 infectivity by MAPK, a virion-associated kinase," The EMBO Journal, vol. 17, no. 9, pp. 2607-2618, 1998.

[95] W. Popik, J. E. Hesselgesser, and P. M. Pitha, "Binding of human immunodeficiency virus type 1 to CD4 and CXCR4 receptors differentially regulates expression of inflammatory genes and activates the MEK/ERK signaling pathway," Journal of Virology, vol. 72, no. 8, pp. 6406-6413, 1998.

[96] X. Yang and D. Gabuzda, "Regulation of human immunodeficiency virus type 1 infectivity by the ERK mitogen-activated protein kinase signaling pathway," Journal of Virology, vol. 73, no. 4, pp. 3460-3466, 1999.

[97] D. A. Frank and M. E. Greenberg, "CREB: a mediator of longterm memory from mollusks to mammals," Cell, vol. 79, no. 1, pp. 5-8, 1994.

[98] K. C. Martin and E. R. Kandel, "Cell adhesion molecules, CREB, and the formation of new synaptic connections," Neuron, vol. 17, no. 4, pp. 567-570, 1996.

[99] A. J. Silva, J. H. Kogan, P. W. Frankland, and S. Kida, "CREB and memory," Annual Review of Neuroscience, vol. 21, pp. 127-148, 1998.

[100] H. Wen, Y. Lu, H. Yao, and S. Buch, "Morphine induces expression of platelet-derived growth factor in human brain microvascular endothelial cells: implication for vascular 
permeability," PLoS ONE, vol. 6, no. 6, Article ID e21707, 2011.

[101] J. Wang, R. A. Barke, R. Charboneau, H. H. Loh, and S. Roy, "Morphine negatively regulates interferon- $\gamma$ promoter activity in activated murine $\mathrm{T}$ cells through two distinct cyclic AMP-dependent pathways," The Journal of Biological Chemistry, vol. 278, no. 39, pp. 37622-37631, 2003.

[102] T. F. Deuel, "Polypeptide growth factors: roles in normal and abnormal cell growth," Annual Review of Cell Biology, vol. 3, pp. 443-492, 1987.

[103] M. Hannink and D. J. Donoghue, "Structure and function of platelet-derived growth factor (PDGF) and related proteins," Biochimica et Biophysica Acta, vol. 989, no. 1, pp. 1-10, 1989.

[104] C. H. Heldin, "Structural and functional studies on plateletderived growth factor," The EMBO Journal, vol. 11, no. 12, pp. 4251-4259, 1992.

[105] R. Potula, N. Dhillion, Y. Sui et al., "Association of platelet-derived growth factor-B chain with simian human immunodeficiency virus encephalitis," American Journal of Pathology, vol. 165, no. 3, pp. 815-824, 2004.

[106] E. J. Su, L. Fredriksson, M. Geyer et al., "Activation of PDGFCC by tissue plasminogen activator impairs blood-brain barrier integrity during ischemic stroke," Nature Medicine, vol. 14, no. 7, pp. 731-737, 2008.

[107] H. Yao, M. Duan, and S. Buch, "Cocaine-mediated induction of platelet-derived growth factor: implication for increased vascular permeability," Blood, vol. 117, no. 8, pp. 2538-2547, 2011. 


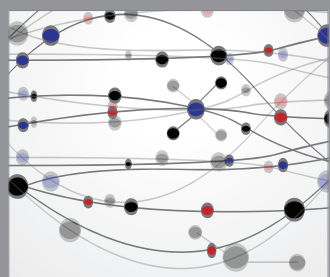

The Scientific World Journal
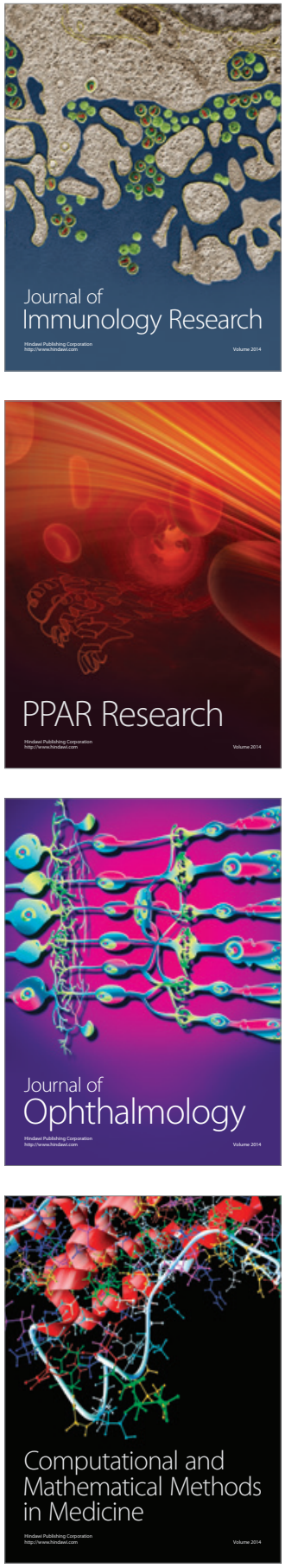

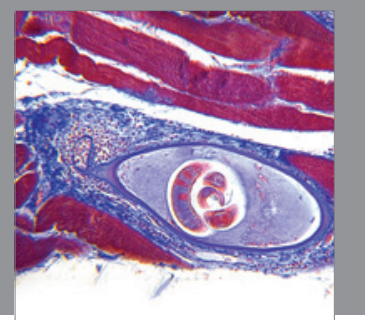

Gastroenterology

Research and Practice
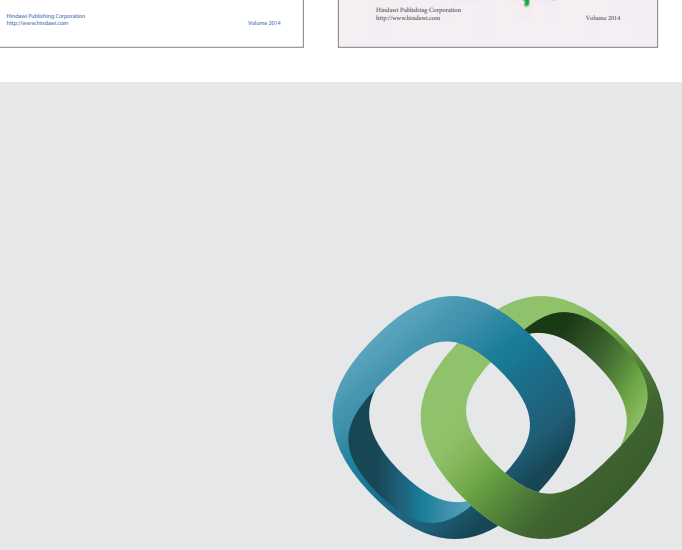

\section{Hindawi}

Submit your manuscripts at

http://www.hindawi.com
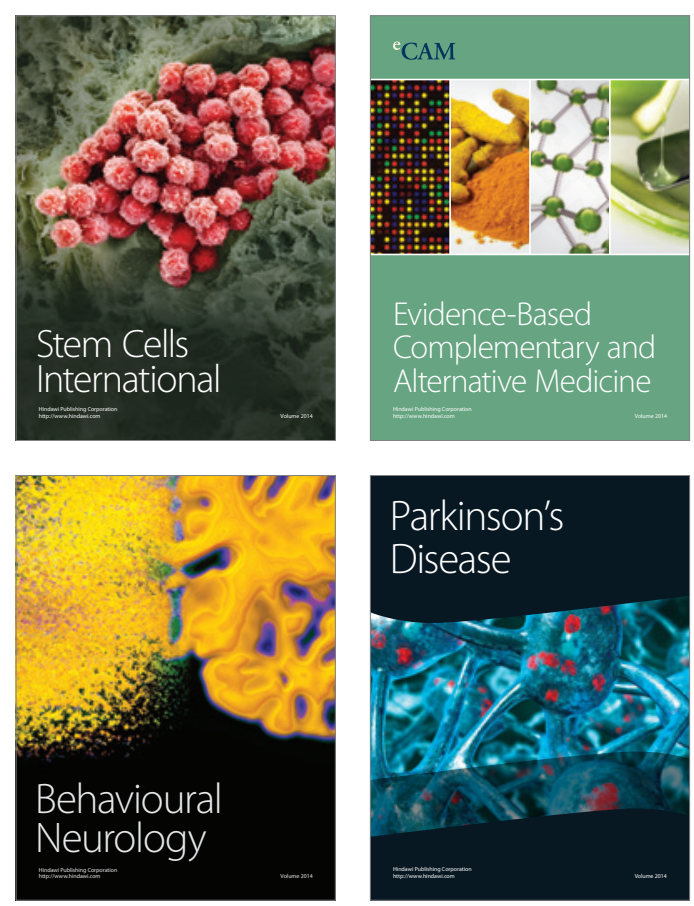

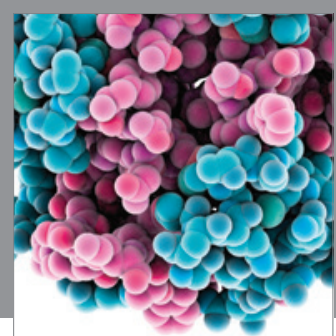

Journal of
Diabetes Research

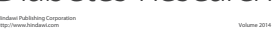

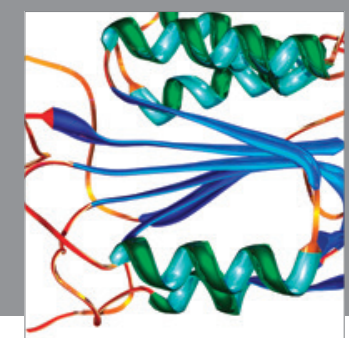

Disease Markers
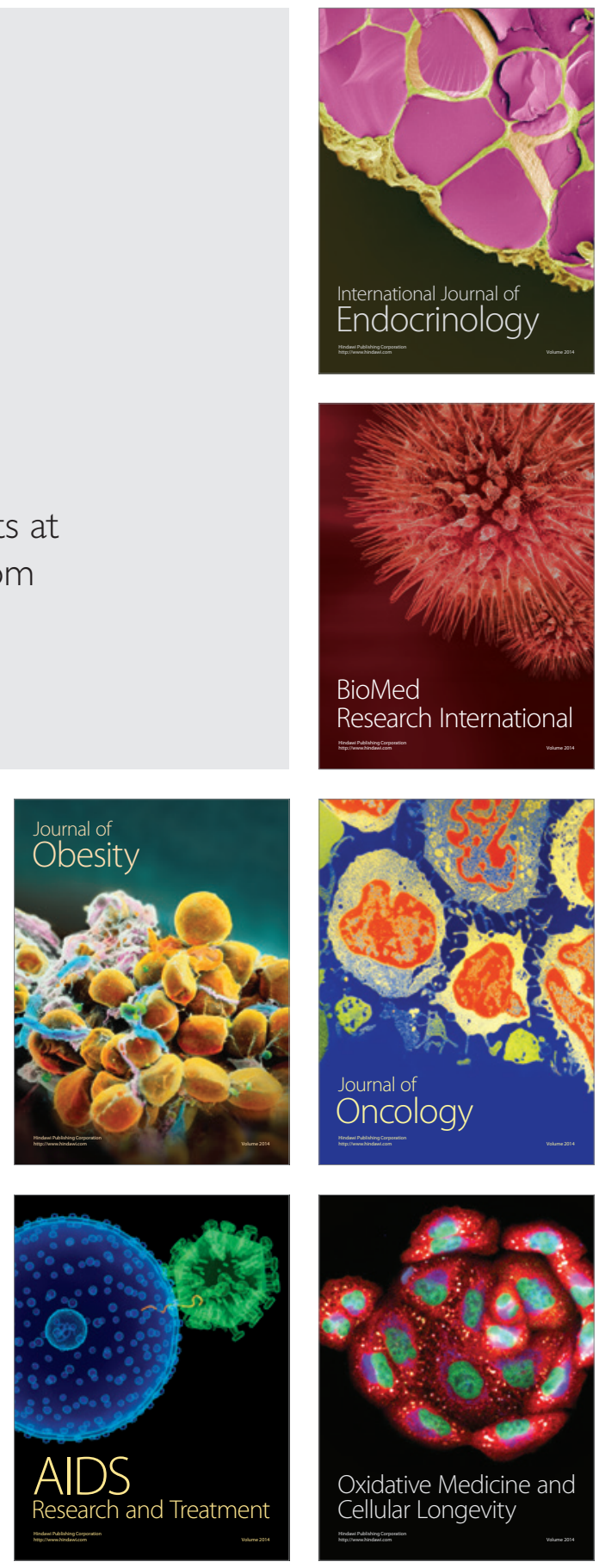